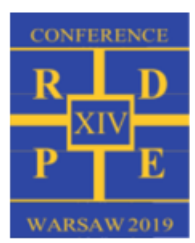

\title{
Thermodynamic analysis of the Compressed Air Energy Storage system coupled with the Underground Thermal Energy Storage
}

\author{
Rafał Hyrzyński ${ }^{1}$, Paweł Ziółkowski ${ }^{2, *}$, Sylwia Gotzman ${ }^{1}$, Bartosz K raszewski ${ }^{1}$ and Janusz Badur ${ }^{1}$ \\ ${ }^{1}$ Institute of Fluid-Flow Machinery, Polish A cademy of Sciences, Fiszera 14, 80-231 Gdańsk, rafal.hyrzynski@imp.gda.pl, \\ Bartosz.kraszewski@imp.gda.pl, jb@imp.gda.pl, Poland \\ 2 Gdańsk University of Technology, Faculty of Mechanical Engineering, Narutowicza 11/12, 80-233 Gdańsk, e-mail: \\ pawel.ziolkowski1@pg.edu.pl, Poland
}

\begin{abstract}
Improvement of flexibility is one of the key challenges for the transformation of the Polish Power System aiming at a high share of renewable energy in el ectricity generation. Flexible and dispatchable power plants will contribute to this ongoing transformation process as they compensate for fluctuations in electricity generation from renewable energy sources such as wind and photovoltaics. In this context, CAES storage tanks are currently the only alternative to storage facilities using pumped-storage hydroelectricity due to the possibility of obtaining the appropriate energy capacity of the storage facility. However, a relative disadvantage of these plants is the heat loss caused by the cooling of the air after compression. The basic elements of the CAES warehouse are: an air compression station, a compressed air reservoir that is also a storage facility (in the existing solutions, these are underground caverns), an expansion station with combustion chambers and gas turbines, and a generator. A key aspect of CAES is the optimal configuration of the thermodynamic cycle. In this paper, the situation of cooperation between the current conventional power plants and wind farms is first analysed, and then, based on thermodynamic models, the process of storing thermal and electrical energy in the CAES system coupled with heat recovery after the gas turbine is analysed. A solution with a ground heat exchanger was also proposed, as the soil, due to its properties, may serve as a thermal energy storage. The paper also analyzes the discharge of the heat storage based on CFD approaches. The ground can be charged during the cooling down of the compressed air. On the other hand, thermal energy was recovered when water flowing to the heat customers was heated. On the basis of non-stationary calculations, the heat stream received from the underground thermal energy storage was estimated.
\end{abstract}

\section{Introduction}

Currently, due to the development of renewable energy, the variability of operation of conventional units will be one of the most noticeable consequences of the transformation of the Polish Power System (PSE, Polskie Sieci Elektroenergetyczne SA) [1], and this involves one of the most important aspects of PSE, namely its stability. Therefore, it is worthwhile to integrate energy storage into the intermittent energy sources in order to increase their flexibility, inter alia, by building CAES (Compressed Air Energy Storage) systems.

Additionally, it should be remembered that the activities of the UN (through the Conference of the Parties, COP) significantly affect the global energy policy of most countries or even regions of the world, and in particular the policy of the European Union. It is in the framework of climate and energy policy that the EU has defined three key objectives until 2030:

1. a reduction of at least $40 \%$ in greenhouse gas emissions (compared to 1990 levels),

2. ensure at least a $27 \%$ share of energy from renewable sources in total energy consumption,

3. increase energy efficiency by at least $27 \%$.
Precisely these targets were adopted by the European Council of 23-24 October 2014 [2]. Therefore, more or less successful synergy between solar and wind energy will inevitably occur, characterised by significant unpredictability and intermittence of work with traditional systems that are able to store either electricity or mechanical energy. It partly forces also the situation, when conventional sources connected to the power system have to compensate the fluctuating electricity generation from the weather-dependent energy sources such as wind and photovoltaics [3]. In order to illustrate the volatile character of electricity generation from wind sources, the authors selected two significant profiles of electricity generation from wind farms, starting from 1 January 2019 until $21 \mathrm{M}$ ay 2019. The full range of profiles can be found in the work by Badur et al. [4]. For Figures 1 and 2, the left-hand axis refers to the "Load of Polish Power System" and "Load covered without WFs (W ind Farms)", while the right-hand axis refers to "Total WFs Generation". Figure 1 shows the Polish Power System operation from 1 January 2019 to 21 M ay 2019, which shows a characteristic variability depending on the work schedule of customers, in particular industrial ones, and 
on weather conditions, seasons, cultural, social events,

etc. [5].

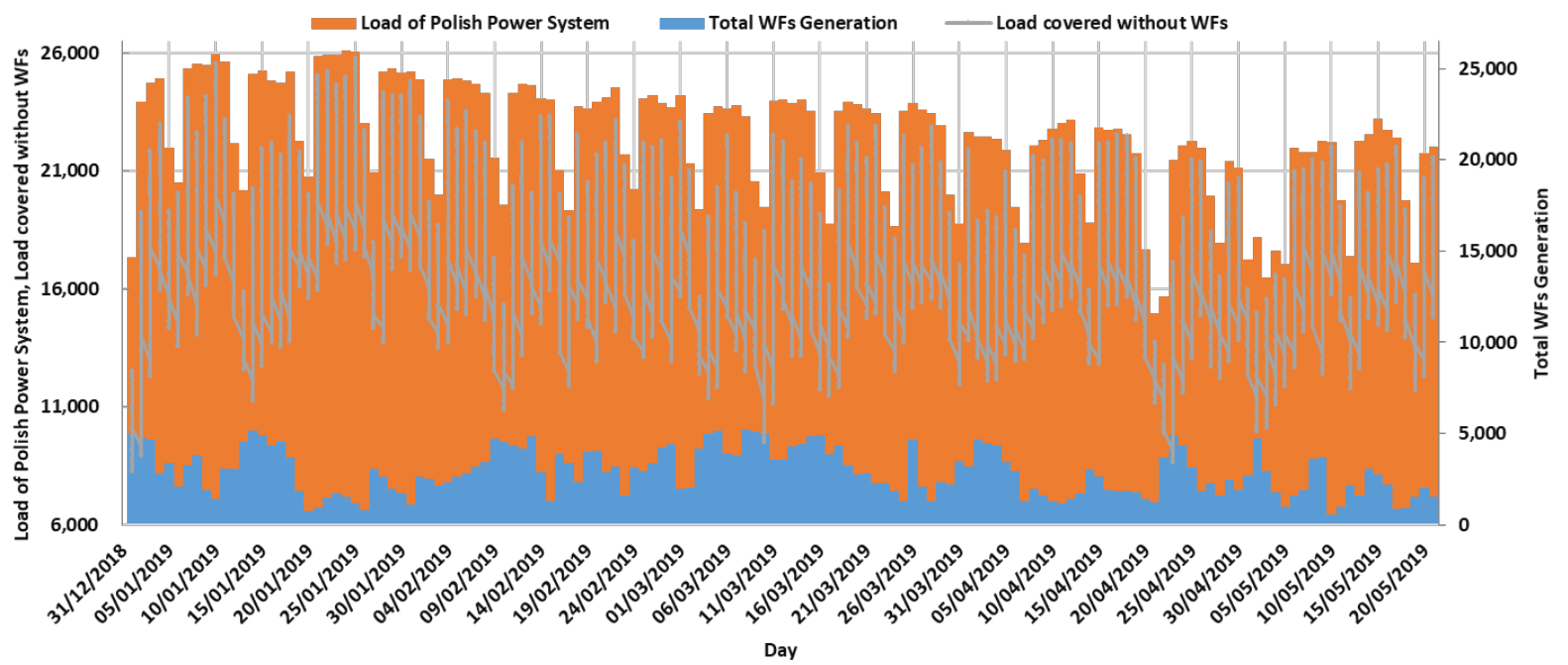

Fig. 1. Electricity production in Poland in the period from 1 J anuary 2019 to $21 \mathrm{M}$ ay 2019 (M W). The data may differ from the data presented by the TSO due to the fact that the data available on the TSO platform are published with $1 \mathrm{~h}$ resolution (not $15 \mathrm{~min}$ ).

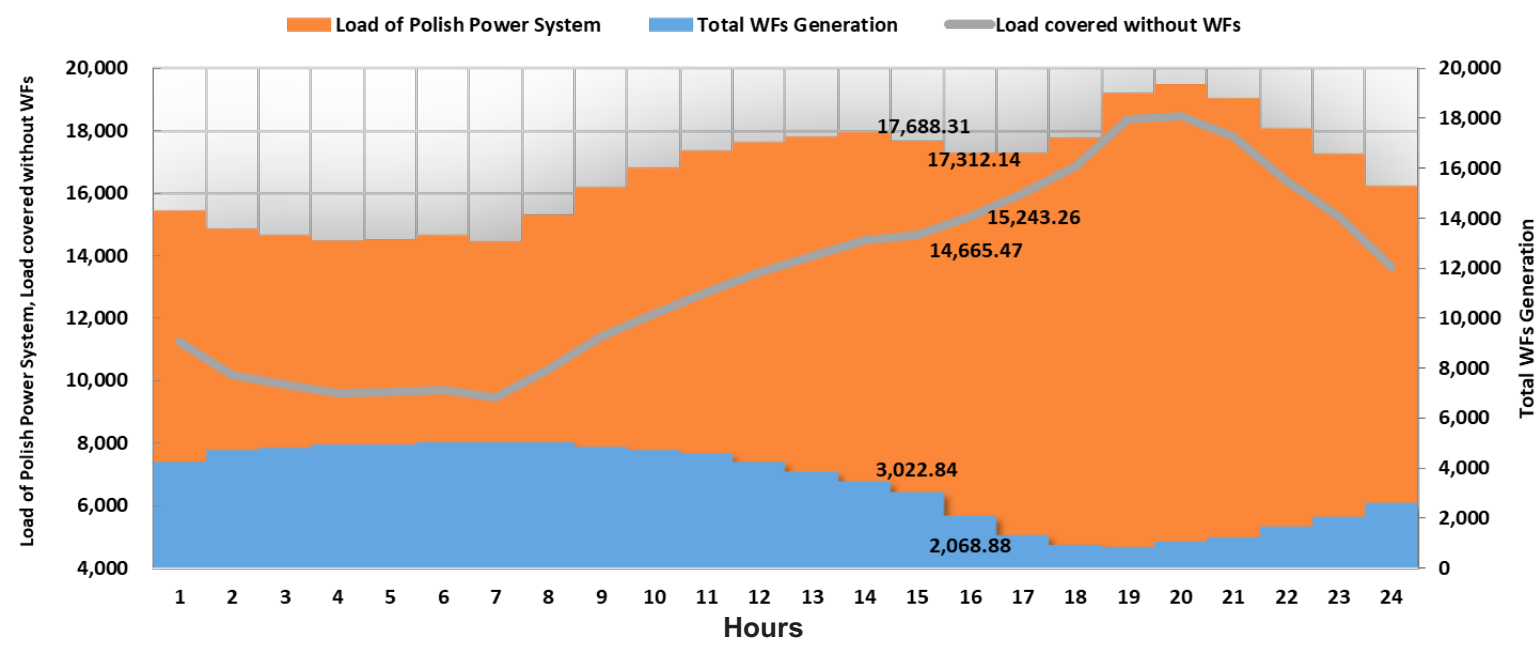

Fig. 2. Electricity production in Poland on the day on which the maximum 2-hour generation power variation from W F s occurred (954 M W; 10 M arch 2019 between 3 p.m. and 4 p.m.) [M W ]. The data may differ from the data presented by the TSO due to the fact that the data available on the TSO platform are published with $1 \mathrm{~h}$ resolution (not $15 \mathrm{~min}$ ).

However, the wind energy generation throughout the Sunday of M arch 10, 2019 (Figure 2), deserves a more detailed analysis. This is because on that day the maximum hourly variability of power generation from wind farms occurred. This situation took place between 3 p.m. and 4 p.m. During the hour the change of wind power output amounted to -954 M W. A that time, the change in the load of the Polish Power System alone amounted to $376 \mathrm{M} \mathrm{W}$. This means that this sudden reduction in the power generation from the wind farms forced other sources included in the power system to increase their generation by $578 \mathrm{MW}$ over the course of 60 minutes. This value is close to the total installed capacity of the three units of Ostrołęka power plant (690 MW) and, what is more, required on short notice. This single case of wind farm capacity reduction is obviously not too much of a challenge for the Transmission System Operator (TSO) (in the absence of emergency situations, e.g. sudden failure of a large unit in the system or failure of several units). Such a power loss (frequency drop in the system) can be quickly replenished by launching several hydropower units in pumped-storage power plants for generation operation mode, using the possibility of increasing capacity on cross-border connections in the direction of import, as well as by forcing the opening of regulatory valves in individual conventional generating units, which results in adjusting generation to the load and restoring balance [7].

On the other hand, Fig. 3 presents electricity generation and consumption on the day when there was a minimal difference between the generation from W Fs and the load of the Polish Power System (8258.24 MW; 1 
J anuary 2019 at 9 a.m.). The following types of generating units should are presented on the graph: industrial combined heat and power plants (ICHP), power sector combined heat and power plants (PCHP), centrally dispatched power plants (PP), and pumped-storage hydroel ectricity (PSE). During the whole year, the energy generated in RES is dispatched first, and according to the data from [6] it amounted to: 4,735 M W. N ext in a series of energy conversions, especially in winter, are both industrial and power sector CHP plants, which at that time reached the capacity of $289 \mathrm{MW}$ and 1,162 MW respectively. On the other hand, centrally dispatched power plants generated electricity both for pumped storage power plants $(1,423 \mathrm{MW})$ and for average consumers $(4,635 \mathrm{M} \mathrm{W})$. This figure shows that the only valuable energy storage at this point in time is pumped storage and there are no al ternatives.

A $n$ increase in the installed capacity of sources which are difficult to forecast will require more sophisticated countermeasures from the TSOs (in case of sudden reduction or increase in the capacity generated in these sources). On the other hand, an increase in the capacity of variable RES will force operators of conventional units to modernize their generating units in order to increase their flexibility understood as [8]: the ability to safe unit operation in planned transient conditions, while taking actions to control the generating unit. This notion applies both to changes in the load of the unit, as well as to its provisioning or restarting. This issue is so complex and still open, and one of the alternatives is CA ES-type energy storage.

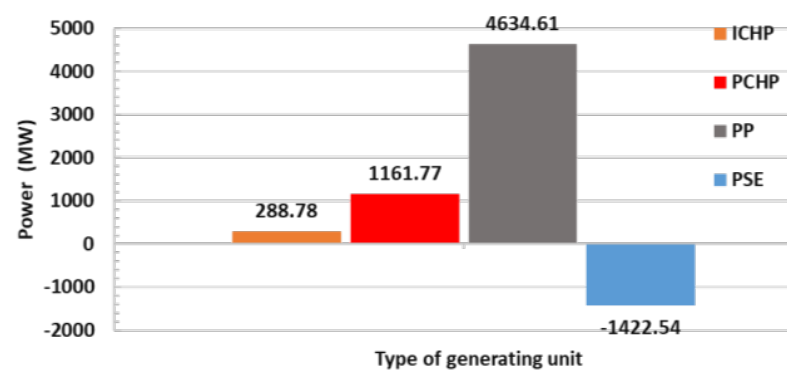

Fig. 3. Electricity production on the day when there was a minimal difference between the generation from WFs and the load of the Polish Power System (8258.24 M W ; 1 January 2019 at 9 a.m.). (M W ).

CAES storage tanks are currently the only alternative to storage facilities using pumped-storage hydroelectricity due to the possibility of obtaining the appropriate energy capacity of the storage facility. However, a relative disadvantage of these plants is the heat loss caused by the cooling of the air after compression. There are currently two commercial systems in operation worldwide on a large scale. First commissioned in Huntorf in 1978 in Germany with a capacity of $290 \mathrm{M} \mathrm{W}$ and $580 \mathrm{M} \mathrm{Wh}$, and M clntosch with a capacity of $110 \mathrm{M} \mathrm{W}$ and $2860 \mathrm{M} \mathrm{Wh}$ in the US.

In general, three systems can be distinguished [9]:

a) standard system (without using the exhaust heat from the gas turbine exhaust - the system used in the Huntorf Power Plant), b) with recuperation (using the exhaust heat from the gas turbine exhaust - the system applied in the M cIntosh Power Plant),

(c) adiabatic (non-fuel).

However, new CAES-based energy storage technologies have developed in recent years, namely Underwater Compressed Air Energy Storage also called Ocean Compressed Air Energy Storage [10], Second Generation Compressed Air Energy Storage [11], Isothermal Compressed Air Energy Storage [12], Low Temperature Compressed Air Energy Storage [13], Advanced Adiabatic Compressed Air Energy Storage [14], Liquid Air Energy Storage [15]. However, simple CAES systems with and without heat regeneration are of the greatest practical importance [16].

The CAES system without heat recuperation is associated with large losses due to the high temperature of the flue gases behind the gas turbine, which are directed directly to the chimney. A nother source of losses is the compressor, from which the thermal energy released during the compression of the air is taken up in the compressed air tank (cavern). Therefore, the efficiency of energy storage in such a system is low, and the only benefits result from improving the efficiency of the gas turbine cycle operating in a simple system. In order to obtain a relatively high efficiency index of the energy storage cycle, i.e. about 0.50 , heat recovery systems from exhaust gases are used [9.16].

A $n$ adiabatic (fuel-free) system remains in the sphere of research and as such has not yet been implemented, but its advantage is theoretically possible to achieve a storage cycle efficiency of approximately 0.7 , without the need to use fuel. The main technological limitation is the necessity of effective accumulation of thermal energy from the air compression process [16].

Taking into account the above arguments, it was decided to analyze the system with heat regeneration. The aim of this paper is to analyse thermodynamic CAES and preliminary thermal-FSI (Fluid-Solid Interaction) analysis of the heat storage system, which in this case is the ground. The next section presents a diagram and model for CFM (Computational Flow Mechanics) analyses, while the third section is an introduction to thermal-FSI analyses and contains the first step, which in this case is the analysis of heat exchange in the ground.

\section{System description}

The basic elements of CAES system are: 1) air compression station, 2) compressed air reservoir being at the same time a mass storage (in the existing solutions they are underground caverns), 3) expansion station with combustion chambers and gas turbine and generator. The basic elements are a low-pressure compressor $\left(C_{1}\right)$, which, together with high-pressure compressors $\left(C_{2}-C_{4}\right)$ and intersection cooling exchangers $\left(I C_{1}-\mid C_{3}\right)$, increases the pressure of the storage medium up to 60 bar. A cavern (CAV) is the storage place for mass and mechanical energy, which is emptied at the moment of electricity demand. For that purpose, the air is first heated in a regenerative heat exchanger $(\mathrm{HE})$ and then in the first combustion chamber $\left(\mathrm{CC}_{1}\right)$ to increase its enthalpy and 
thus prepare it for partial expansion in the high-pressure turbine $\left(G T_{1}\right)$. Finally, the second combustion chamber $\left(C_{2}\right)$ is used to increase enthal py of exhaust gases, which expands into a low-pressure turbine $\left(G T_{2}\right)$. The underground thermal energy storage (UTES) is a novelty in this case and it is analysed as 2D geometry in Computational Fluid Dynamics (CFD) codes.

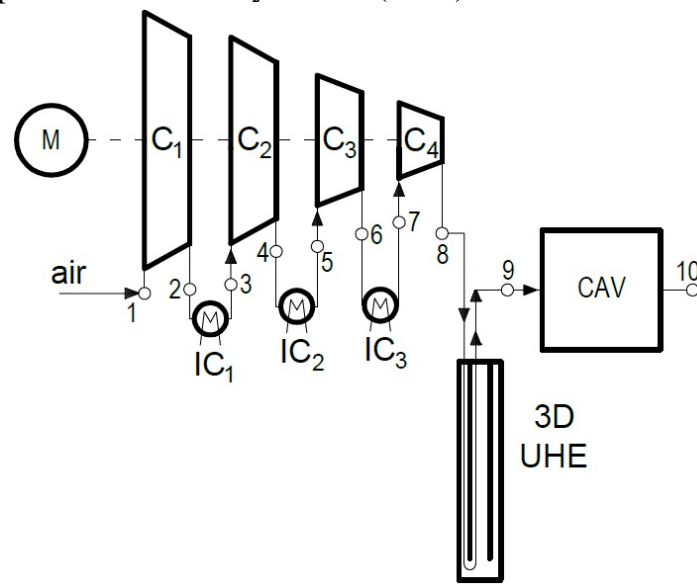

The working pressure in the CAES system determines the required volume of the storage cavern depending on the amount of accumulated energy - for the air pressure in the cavern of about $8 \mathrm{MPa}$ the density of stored energy is $7.5 \mathrm{kWh} / \mathrm{m}^{3}$, while for the pressure of $2 \mathrm{MPa}$ the density of energy stored decreases to only $2 \mathrm{~kW} \mathrm{~h} / \mathrm{m}^{3}$.

Fig. 4. Scheme of the CAES system, where: $C_{1}-$ low pressure compressor, $C_{2}-C_{4}-$ high pressure compressors, $I C_{1}-I C_{3}-$ intersection cooling exchangers, $\mathrm{CC}_{1}-\mathrm{CC}_{2}$ - combustion chambers, $\mathrm{GT}_{1}$ - high pressure turbine, $\mathrm{GT}_{2}$ - low pressure turbine, $\mathrm{HE}$ regenerative heat exchanger, UHE - underground heat exchanger, G - electric generator, $M$ - motor.

The thermodynamic model has the following assumptions: regenerative heat exchanger efficiency $\eta_{H E}=0.8$, isentropic efficiency of compressors $\eta_{i c}=0.81$, mechanical efficiency $\eta_{m c}=0.99$, isentropic efficiency of expanders $\eta_{i G T}=0.85$, generator efficiency $\eta_{g}=0.99$. An additional assumption may be the power output by a gas turbine and in such case the mass streams are the resultant parameters. For compressor calculations such parameters as internal efficiency $\eta_{i c}$ and mechanical efficiency $\eta_{m c}$, compression ratio $\pi$ and mass flow rate of air $\dot{m}_{a}$ are given as input data. Knowing the gas parameters at the compressor inlet, e.g. $\left(T_{1}, p_{1}\right)$ we easily calculate the pressure $p_{2}$ after the compression change:

$$
p_{2}=\pi p_{1}
$$

The next step is to determine the temperature at the end of compression, where for the ideal process we use the equation of isentropes, $s=i d e m$ :

$$
T_{2 s}=T_{1}\left(\frac{p_{2}}{p_{1}}\right)^{\frac{\kappa-1}{\kappa}}
$$

where the $\kappa$ of the isentropic exponent is determined on the basis of thermodynamic property tables of a given working medium. In order to determine the actual temperature of the end of compression $T_{2}$, one should take into account the isentropic efficiency of the compressor's stages $\eta_{i c}$, which is expressed by the formula:

$$
\eta_{i C}=\frac{l_{t 1-2 s}}{l_{t 1-2}}=\frac{h_{1}-h_{2 s}}{h_{1}-h_{2}}
$$

where: $l_{t 1-2 s}$ is the isentropic specific compression work, $l_{t 1-2}$ means the actual specific compression work, $h_{1}, h_{2}, h_{2 s}$ are the specific enthalpy of the working substance in characteristic points (1), (2), (2s). The expander parameters are defined in the same way. The power consumed by the 4 compressors' stages, $N_{C}$, is determined by the following formula:

$$
\begin{aligned}
N_{C}=\frac{\dot{m}_{a}}{\eta_{m c}}\left[\left(h_{2}-\right.\right. & \left.h_{1}\right)+\left(h_{4}-h_{3}\right) \\
& \left.+\left(h_{6}-h_{5}\right)+\left(h_{8}-h_{7}\right)\right]
\end{aligned}
$$

where: $\dot{m}_{a}$ - air mass flow rate, $\eta_{m c}$ - mechanical efficiency of the compressor, and $h_{1} \div h_{8}$ are the specific enthalpy of the working substance in characteristic points $1 \div 8$ (Fig. 4). For energy storage, the amount of stored energy becomes relevant, which can be determined by taking into account the time $\tau$ using the following relationship:

$$
E_{C}=N_{C} \tau_{C}
$$

where: $\tau_{C}$ cycle time of compressors to fill a cavern with air at a pressure of $6 \mathrm{M} \mathrm{Pa}$ and may be different from the cycle time of a turbine $\tau_{G T}$. Equations (1-5) can be used in a similar way for expanders description, but it is worth repeating the most important parameter, which is the energy generated by the turbine during one cycle in cooperation with the cavern:

$$
E_{T}=N_{G T} \tau_{G T}
$$

where: $N_{G T}$ is the total power of the turbines. The mass and energy balance equations of combustion chambers were used to determine the parameters at the inlet to individual turbines. It is worth recalling the energy-flux balance equation of the combustion chambers $\left(\mathrm{CC}_{1}\right)$ : 


$$
\eta_{C C}\left(\dot{Q}_{c h e m 1}+h_{11} \dot{m}_{a}+h_{f} \dot{m}_{f 1}\right)=h_{12} \dot{m}_{12}
$$

where: $\eta_{C C}$ - combustion chamber efficiency, $h_{11}$ oxidising agent enthalpy before combustion chamber $\left(C C_{1}\right), h_{f}$ - fuel enthalpy, $\dot{m}_{f 1}$ - fuel mass flow rate, $h_{12}$ flue gas enthalpy, $\dot{m}_{12}$ - exhaust gases mass flow rate and $\dot{Q}_{c h e m 1}$ - chemical energy transfer rate defined as:

$$
\dot{Q}_{\text {chem } 1}=\dot{m}_{f 1} L H V
$$

The lower heating value $(L H V)$ is the amount of heat obtained from the total and complete combustion of a unit quantity of fuel without condensation of water vapour and was assumed to be $50,03 \mathrm{M} \mathrm{J} / \mathrm{kg}$. Equations (7-8) can be used in a similar way for second combustion chamber $\left(C C_{2}\right)$. Of course, total chemical energy transfer rate is equaled $\dot{Q}_{\text {chem }}=\dot{Q}_{\text {chem } 1}+\dot{Q}_{\text {chem } 2}$. Duration of combustion in combustion chambers $\left(\mathrm{CC}_{1}\right.$ and $\left.\mathrm{CC}_{2}\right)$ relates to expansion process in both expanders $\left(\mathrm{GT}_{1}\right.$ and $\mathrm{GT}_{2}$ ). Therefore, the time of transferring the heat during combustion is equal to the time $\tau_{G T}$, which means that the energy supplied to the combustion chambers is expressed as:

$$
E_{F}=\dot{Q}_{c h e m} \tau_{G T}
$$

Bearing in mind the above data, the efficiency of electricity storage in the CAES system can be defined as follows $[17,18]$ :

$$
\eta_{C A E S}=\frac{E_{T}}{E_{C}+E_{F}}
$$

Taking into account Fig. 4 and the presented model, it was assumed that the temperature of $t_{12}=600^{\circ} \mathrm{C}$ will be reached in the first combustion chamber $\left(\mathrm{CC}_{1}\right)$ and $t_{14}=1100^{\circ} \mathrm{C}$ in the second combustion chamber $\left(\mathrm{CC}_{2}\right)$. Therefore, assuming thermodynamic parameters as for the existing installations, both for the gas turbine and for the compressor, the calculations were carried out with the assumption of a generator capacity of $30 \mathrm{MWe}$. The efficiency of this system according to equation (10) amounted to $\eta_{\text {CAES }}=0.52$, which is a satisfactory value given the volatility of renewable energy sources such as wind and photovoltaics.

\section{Preliminary thermal-FSI analysis}

The preliminary thermal-FSI analysis was carried out for a uniform soil with the following parameters: density $1900 \mathrm{~kg} / \mathrm{m}^{3}$, heat conduction coefficient $2.2 \mathrm{~W} /(\mathrm{mK})$, specific heat $980 \mathrm{~J} /(\mathrm{kgK})$. A natural temperature gradient of $3^{\circ} \mathrm{C} / 100 \mathrm{~m}$ was assumed. The computational domain of the diameter of $1 \mathrm{~km}$ reached into the ground at the depth of $5 \mathrm{~km}$. The Field's ground exchanger, on the other hand, according to its geometry, can draw or deliver a heat stream at a depth of $4 \mathrm{~km}$, and it consists of an inner pipe of $76 \mathrm{~mm}$ diameter and an outer pipe of $318 \mathrm{~mm}$ diameter. The pressure at the inlet has been set at the outer pipe as $3,1 \mathrm{M} \mathrm{Pa}$ and the temperature as $70^{\circ} \mathrm{C}$ with the water mass flow rate of $5,3 \mathrm{~kg} / \mathrm{s}$. The outlet pressure at the inner pipe, taking into account the calculated pressure drop, was 2
MPa. The system of equations solved to determine the transient liquid temperature profiles is worth quotining here $[19,20]$ :

$$
\begin{aligned}
\frac{\partial}{\partial t}\left\{\begin{array}{c}
\rho \\
\rho \mathbf{v} \\
\rho e \\
\rho k \\
\rho \omega
\end{array}\right\}+\operatorname{div}\left\{\begin{array}{c}
\rho \mathbf{v} \\
(\rho \mathbf{v} \otimes \mathbf{v})+p \mathbf{I} \\
(\rho e+p) \mathbf{v} \\
\rho \mathbf{v} k \\
\rho \mathbf{v} \omega
\end{array}\right\} \\
=\operatorname{div}\left\{\begin{array}{c}
0 \\
\mathbf{t}^{\mathrm{c}} \\
\mathbf{t}^{\mathrm{c}} \mathbf{v}+\mathbf{q}^{\mathrm{c}} \\
\mathbf{J}_{k} \\
\mathbf{J}_{\omega}
\end{array}\right\}+\left\{\begin{array}{c}
0 \\
\rho \mathbf{b} \\
\rho S_{e} \\
\rho S_{k} \\
\rho S_{\omega}
\end{array}\right\}
\end{aligned}
$$

where: $\rho$ - density, $\mathbf{v}$ - velocity, $p$ - pressure, I - unit tensor, $\mathbf{t}^{\mathbf{c}}$ - viscous stress tensor, $\mathbf{b}$ - the force of earth's gravitation, $e=u+\frac{1}{2} \mathbf{v}^{2}$ - the sum of internal and kinetic energy, $\mathbf{q}^{c}$ - total heat flux, $\mathbf{J}_{k}, \mathbf{J}_{\omega}$ - diffusion flux of turbulent kinetic energy $k$ and diffusion flux of kinetic energy dissipation $\omega$. In equation (11) is source of turbulent kinetic energy $S_{k}$ and source of turbulent kinetic energy dissipation $S_{\omega}$. This equation is complemented by heat conduction in the solid - the soil. The analyzed domains, on the example of the end of the exchanger, have been presented in Fig. 5.

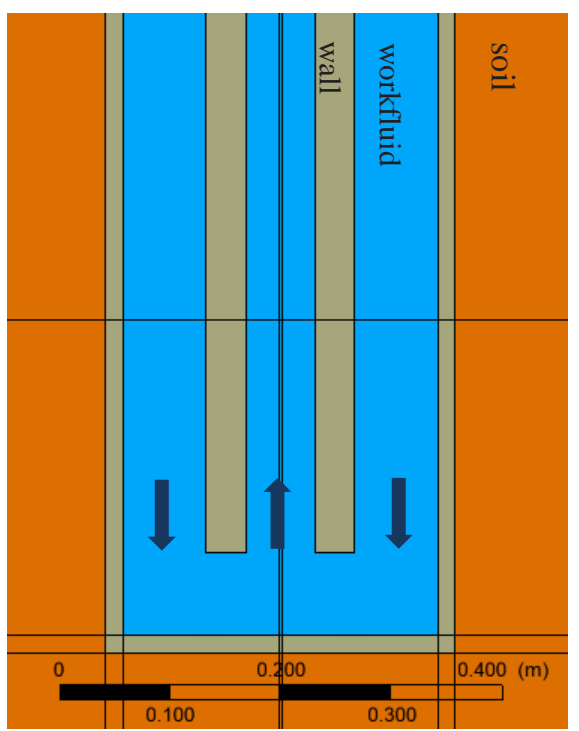

Fig. 5. The lower end of the underground heat exchanger.

The analysis was made in 2D axially-symmetrical form - the domains' axis coincides with the axis of the exchanger. Considering mixing and recurrence of the medium at the lower end of the exchanger, the k-omega SST turbulence model has been chosen. The 2D mesh $(0.5$ $x 5 \mathrm{~km}$ ) rotated around the pipe axis consists of 825956 elements. The sample of the discretization of the ground, pipes and working fluid is shown in Fig. 6 .

To minimalize simulation errors the heat exchanger, the ground and the working fluid under consideration has been divided into some blocks that have been discretized by means of a structured numerical grid, steeply refined in the normal wall direction. Initial tests allowed to use the numerical grid to ensure that further refinement did 
not influence the computational results. It has been assumed that the surface structure of the pipes can be treated as a homogeneous one. Wall function has been implemented at the level 50. The standard SIM PLE (semiimplicit method for pressure-linked equations) method has been employed for pressure-velocity coupling. The second order upwind schemes have been chosen for the solution of the convection term in governing equations. The diffusion terms have been central-differenced with the second order accuracy as well. The detailed methodology of numerical integration regarding the set of governing equations can be found in work [20].

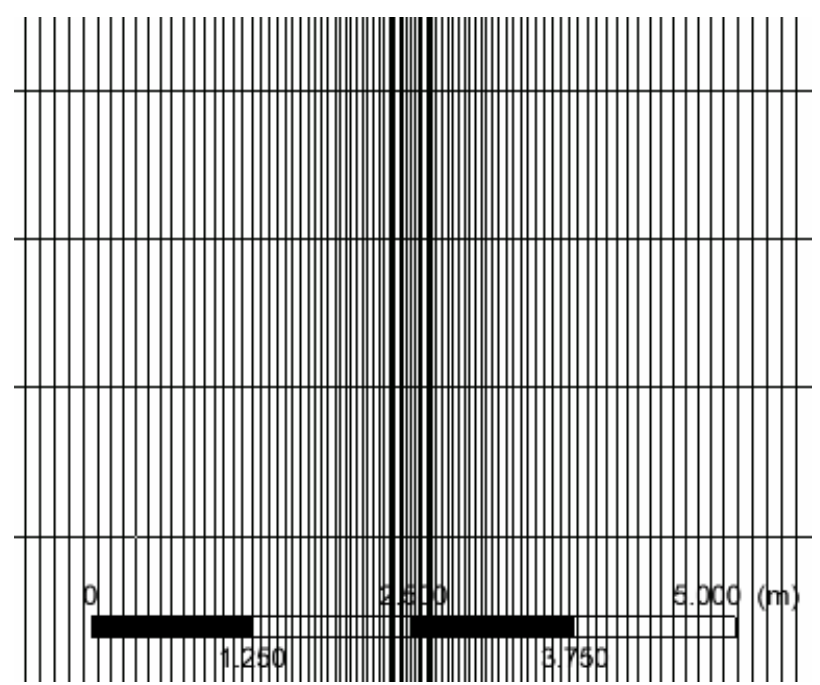

Fig. 6. A sample of discretization of the analyzed domains.

In the preliminary calculations, which are performed at the present level of detail, water is used as the working fluid. It was also assumed that the inner pipe is an ideal insulator and that there is no heat transfer between the fluids. The average temperature at the outl et of the ground heat exchanger over time is presented in Fig. 7. The calculations assume that the pipes are initially filled with the working substance and for about 1 hour there is an outflow of the medium accumulated earlier, and only then the average outlet temperature is formed as a result of heating of water from the temperature of $70^{\circ} \mathrm{C}$.

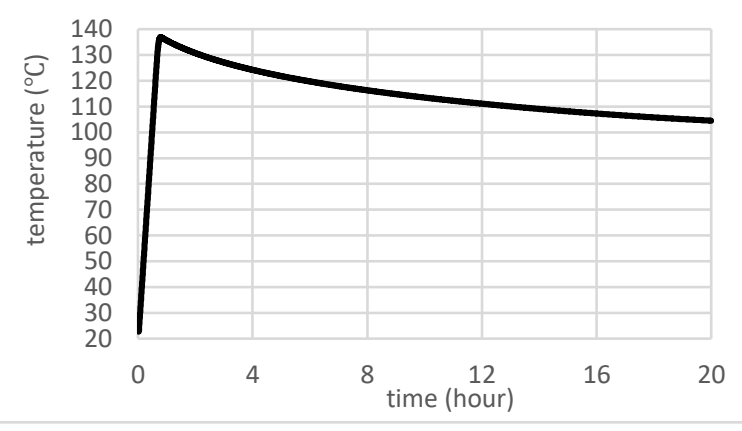

Fig. 7. A verage outlet temperature for non-stationary heat transfer.

Fig. 8 shows the balance of the heat transfer rate obtained from the ground at the outl et from the exchanger. It indicates that at the beginning, the working medium transfers the heat to the soil. After some time the exchanger starts to play the proper role and draws the heat from the ground. The heat transfer rate from the maximum value of 1.4 M W starts to decrease, but does not show any sudden changes, which should be considered positive given the fact that the underground heat exchanger (UHE) will operate on a cyclical basis.

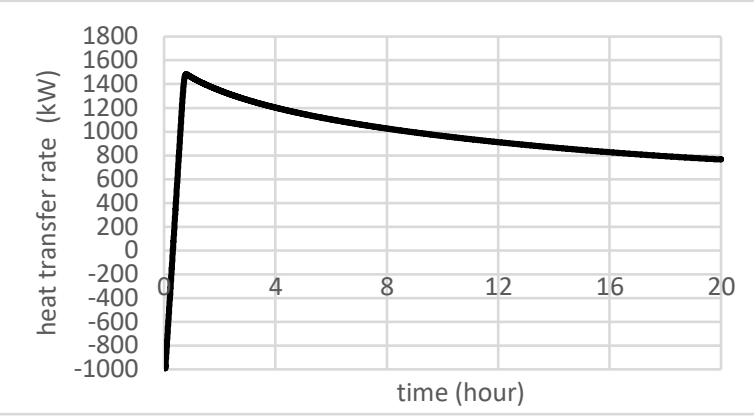

Fig. 8. B al ance of the heat flow obtained from the ground at the outlet of the underground heat exchanger.

The influence of the heat exchanger on the temperature distribution in the ground is presented in Fig. 9. The resulting temperature funnel does not exceed $3 \mathrm{~m}$ in diameter, which suggests the use of smaller computational domains and higher heat exchanger capacities in future analyzes. However, in the literature [21-23] we can find examples of numerical calculations of heat transfer between exchanger and the environment in which the soil domain area is large - similarly scaled as in this paper.

During the charging process, the ground temperature will return to its initial state and in the next operating cycle it will be possible to generate a similar heat flux. In the next stage of work, the dimensions of the underground heat exchanger, loading and unloading time and the number of exchangers will be optimized.

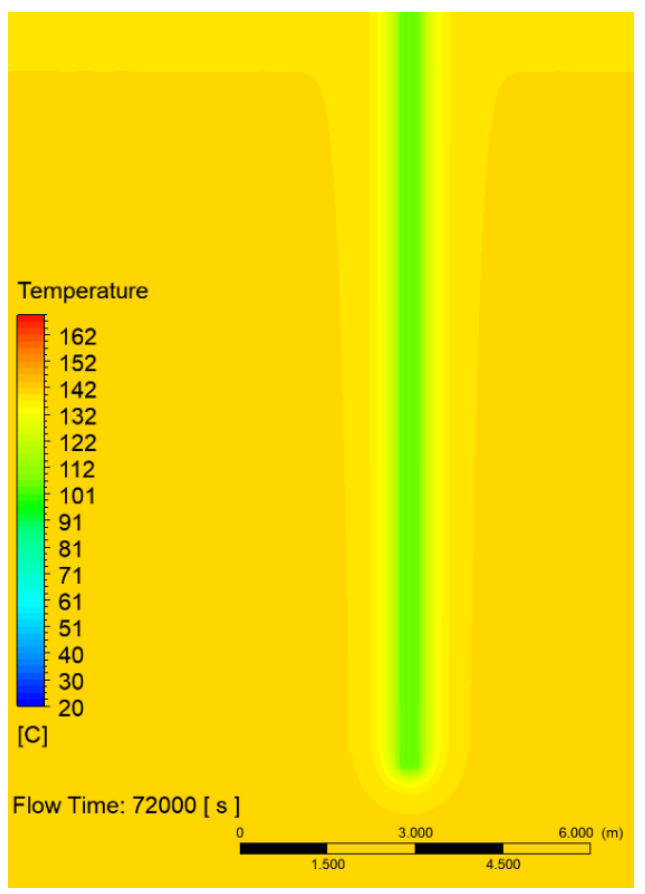

Fig. 9. The temperature distribution at the lower end of the underground heat exchanger after $20 \mathrm{~h}$ of the simulation 


\section{Conclusions}

In this paper, the information concerning the cooperation of variable RES sources with conventional steam power plants were presented. Two situations (Fig.1 and Fig.2) are shown which indicate that there is a need to develop CAES systems. Next, a system is proposed which may improve the operation of the power system to some extent by storing energy in CAES systems. The efficiency of this process of charging and discharging the cavern has been estimated according to the formula (10) at $\eta_{C A E S}=0.52$, which is a satisfactory value, taking into account the irregularity of the work of hardly predictable renewable energy sources such as wind and photovoltaic, whose irregularity will be compensated for. The underground heat exchanger (UHE) may be an element reducing heat losses to the environment from the CAES system and thus increasing the efficiency of energy conversion, but further work is needed on its design and integration into the system.

A CK N OW LEDGEM ENTS Paper was created as part of the statutory work of Institute Fluid-Flow Machinery Polish A cademy of Sciences. However, other part of this work was partially funded by research subvention from Faculty of Mechanical Engineering (No. 033740/DS), Gdańsk University of Technology.

\section{References}

1. Hyrzyński R., Badur J., Jaroszewska M., Ziółkowski P., Gotzman S., Froissart M., Impact of wind turbines on climate, Energetyka,Vol. 776, No 2, pp. 77-83, (2019), [in Polish].

2. The European Council. European Council, 2324.10.2014. Climate and Energy Policy Framework Up to 2030, (2014). https://www.consilium.europa.eu/ $\quad \mathrm{pl} /$ meetings/ european-council/2014/10/23-24/.

3. Klonowicz P., Witanowski Ł., Jędrzejewski Ł., Suchocki T., Surwiło J., Stepniak D., Wstepna analiza potencjału zasobników energii typu UWCAES w Zatoce Gdańskiej, Rynek Energii, Vol. 124, No 3, pp. 100-107, (2016).

4. Badur J., Hyrzyński R., Kraszewski B.. Ziółkowski P., Dudda W., Analysis of electricity generation variability in the first five months of 2019, with particular emphasis on wind energy generation, Nowa Energia Vol. 68, No 3, pp. 40-45, (2019), [in Polish].

5. Wasiak I., Elektroenergetyka $w$ zarysie. Przesyt $i$ rozdział energii elektrycznej, Politechnika Łódzka, Łódź, (2010).

6. Polskie Sieci Elektroenergetyczne SA. System data, Pr KSE 2019. https://www.pse.pl/danesystemowe/praca-kse/informacje-ogolne/opissystemu, [in Polish].

7. Zajczyk R., Regulacja częstotliwości $i$ mocy $w$ systemie elektroenergetycznym, Politechnika Gdańska, Gdańsk, (2002).

8. Polish Wind Energy Association; Lower Silesian Institute of Energy Studies. Cooperation of conventional coal and large scale RES sources, (2019), [in Polish].

9. Li B., DeCarolis JF., A techno-economic assessment of offshore wind coupled to offshore compressed air energy storage, Appl Energy, Vol. 155, pp. 315-322, (2015).

10. Cheung BC., Carriveau R., Ting DSK., Multiobjective optimization of an underwater compressed air energy storage system using genetic algorithm, Energy, Vol. 74, pp. 396-404, (2014).

11. Salvini C., Techno-Economic Analysis of Small Size Second Generation CAES System, Energy Procedia, Vol. 82, pp. 782-788, (2015).

12. Iglesias A., Favrat D., Innovative isothermal oil-free co-rotating scroll compressor-expander for energy storage with first expander tests, Energy Convers Manag, Vol. 85:565-572, (2014).

13. Wolf D., Budt M., LTA-CAES - A low-temperature approach to Adiabatic Compressed Air Energy Storage, Appl Energy, Vol. 125, pp.158-164, (2014).

14. Hartmann N., Vöhringer O., Kruck C., Eltrop L., Simulation and analysis of different adiabatic CAES plant, Appl Energy, Vol. 93, pp. 541-548, (2012).

15. Krawczyk P, Szablowski L, Karellas S, Kakaras E, Badyda K., Comparative energy and exergy analysis of compressed air and liquid air energy storage systems, Proceedings of ECOS 2016 - the 29th International Conference on Efficiency, Cost, Optimization, Simulation and Environmental Impact of Energy Systems, June 19-23, 2016, Portorož, Slovenia.

16. Liu W., Liu L., Zhou L., Huang J., Zhang Y., Xu G., Yang Y., Analysis and Optimization of a Compressed Air Energy Storage-Combined Cycle System, Entropy, Vol. 16, pp. 3103-3120, (2014).

17. Badyda K., Milewski J., Thermodynamic analysis of compressed air energy storage working conditions, Arch Energ, Vol. 42, pp. 53-68, (2012).

18. Szablowski L, Krawczyk P, Badyda K, Karellas S, Kakaras E, Bujalski W., Energy and exergy analysis of adiabatic compressed air energy storage system. Energy, Vol. 138, pp. 12-18, (2017).

19. Badur J., Ziółkowski P., Sławiński D., Kornet S., An approach for estimation of water wall degradation within pulverized-coal boilers, Energy, Vol. 92, pp. 142-152, (2015).

20. Badur J., Numerical modelling of sustainable combustion in gas turbines, IFFM Publishers, Gdańsk, 2003.

21. Lous M., Larroque F., Dupuy A., Moignard A., Thermal performance of a deep borehole heat exchanger: Insights from a synthetic coupled heat and flow model, Geothermics Vol, 57, pp. 157-172, (2015).

22. Hanuszkiewicz-Drapała M., Składzień J., Heating system with vapour compressor heat pump and vertical U-tube ground heat exchanger, Archives of thermodynamics, V ol. 31, N o. 4, pp. 93-110, (2010).

23. Naldi C., Zanchini E., Full-Time-Scale Fluid-toGround Thermal Response of a Borefield with U niform Fluid Temperature, Energies, V ol. 12, 3750; doi:10.3390/en12193750, (2019). 